\title{
Predicting Motor Outcome in Acute Intracerebral Hemorrhage
}

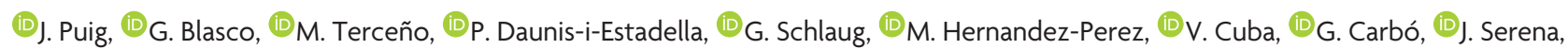

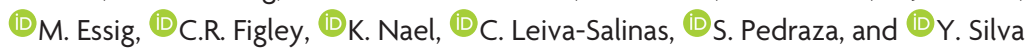

to-

\begin{abstract}
BACKGROUND AND PURPOSE: Predicting motor outcome following intracerebral hemorrhage is challenging. We tested whether the combination of clinical scores and DTI-based assessment of corticospinal tract damage within the first 12 hours of symptom onset after intracerebral hemorrhage predicts motor outcome at 3 months.
\end{abstract}

MATERIALS AND METHODS: We prospectively studied patients with motor deficits secondary to primary intracerebral hemorrhage within the first 12 hours of symptom onset. Patients underwent multimodal MR imaging including DTI. We assessed intracerebral hemorrhage and perihematomal edema location and volume, and corticospinal tract involvement. The corticospinal tract was considered affected when the tractogram passed through the intracerebral hemorrhage or/and the perihematomal edema. We also calculated affected corticospinal tract-to-unaffected corticospinal tract ratios for fractional anisotropy, mean diffusivity, and axial and radial diffusivities. Motor impairment was graded by the motor subindex scores of the modified NIHSS. Motor outcome at 3 months was classified as good (modified NIHSS 0-3) or poor (modified NIHSS 4-8).

RESULTS: Of 62 patients, 43 were included. At admission, the median NIHSS score was 13 (interquartile range $=8-17$ ), and the median modified NIHSS score was 5 (interquartile range $=2-8$ ). At 3 months, 13 (30.23\%) had poor motor outcome. Significant independent predictors of motor outcome were NIHSS and modified NIHSS at admission, posterior limb of the internal capsule involvement by intracerebral hemorrhage at admission, intracerebral hemorrhage volume at admission, 72-hour NIHSS, and 72-hour modified NIHSS. The sensitivity, specificity, and positive and negative predictive values for poor motor outcome at 3 months by a combined modified NIHSS of $>6$ and posterior limb of the internal capsule involvement in the first 12 hours from symptom onset were $84 \%, 79 \%, 65 \%$, and $92 \%$, respectively (area under the curve $=0.89 ; 95 \% \mathrm{Cl}, 0.78-1$ ).

CONCLUSIONS: Combined assessment of motor function and posterior limb of the internal capsule damage during acute intracerebral hemorrhage accurately predicts motor outcome.

ABBREVIATIONS: CST = corticospinal tract; $F A=$ fractional anisotropy; ICC $=$ intraclass correlation coefficient; ICH $=$ intracerebral hemorrhage; IQR $=$ interquartile range; $\mathrm{PHE}=$ perihematomal edema; $\mathrm{PLIC}=$ posterior limb of the internal capsule; $r F A=F A$ ratio

M ore than half of patients with intracerebral hemorrhage (ICH) have residual motor deficits at 6-month follow-up. ${ }^{1}$ Although the severity of the initial motor deficit is one of the most

Received December 18, 2018; accepted after revision March 15, 2019

From the Department of Radiology (J.P., M.E., C.R.F.), University of Manitoba. Winnipeg, Manitoba, Canada; Department of Radiology (J.P., G.B., V.C., G.C., S.P.), Biomedical Research Institute Imaging Research Unit, Diagnostic Imaging Institute, Dr Josep Trueta University Hospital, Girona, Spain; Department of Neurology (M.T.,

J.S., Y.S.), Girona Biomedical Research Institute, Dr Josep Trueta University Hospital, Girona, Spain; Department of Computer Science (P.D.-i.-E.), Applied Mathematics and Statistics, University of Girona, Girona, Spain; Neuroimaging and Stroke Recovery Laboratory (G.S.), Department of Neurology, Beth Israel Deaconess Medical Center and Harvard Medical School, Boston, Massachusetts; Department of Neurosciences (M.H.-P.), Germans Trias i Pujol University Hospital, Autonomous University of Barcelona, Badalona, Spain; Department of Radiology (K.N.), Icahn School of Medicine at Mount Sinai, New York; and Department of Radiology (C.L.-S.), University of Missouri, Columbia, Missouri. important determinants of motor recovery after stroke, growing evidence shows that motor outcome after stroke is heavily dependent on the integrity of the corticospinal tract (CST). ${ }^{2-8}$ Outcome predictions after ICH might be more difficult compared with outcome after ischemic stroke because the damage from ICH includes not only the mass effect but also inflammation and perihematomal edema (PHE), leading to fiber deformations, demyeli-

\footnotetext{
This work was partially supported by a grant from the Spanish Ministry of Health, Instituto de Investigación Carlos III (grant No. 367823-764)

Please address correspondence to Josep Puig, MD, PhD, Department of Radiology, University of Manitoba, 820 Sherbrook St GA216, Winnipeg, MB R3T 2N2, Canada; e-mail: jpuig@hsc.mb.ca

- Indicates open access to non-subscribers at www.ajnr.org

三 Indicates article with on-line tables.

http://dx.doi.org/10.3174/ajnr.A6038
}

AJNR Am J Neuroradiol 40:769-75 May 2019 www.ajnr.org 
nation, and axonal shearing. ${ }^{9}$ Wallerian degeneration in the CST both near and remote from the hematoma is common following ICH. ${ }^{10}$ Whereas conventional MR imaging sequences such as FLAIR and gradient recalled-echo can show the hemorrhage and PHE, DTI depicts and quantifies white matter microstructure by measuring the diffusion of water in tissue. ${ }^{11}$ Lower fractional anisotropy (FA) values along the affected CST remote from the infarct, interpreted as Wallerian degeneration, are associated with greater motor deficit 2-4 weeks after the onset of symptoms and worse motor outcome. ${ }^{12-14}$ Damage to specific CST regions on diffusion tensor tractography can predict limb motor outcome: Involvement of the posterior limb of the internal capsule (PLIC) within the first 12 hours after symptom onset is strongly associated with unfavorable motor outcome at 3 months. ${ }^{15}$ Moreover, the degree of motor deficit correlates higher with lesion-CST overlap than with the lesion size per se. ${ }^{7}$

Although several studies have examined whether DTI-derived data can predict motor outcome in patients with $\mathrm{ICH}$, the results are inconsistent. ${ }^{16-22}$ Both the FA ratio (rFA) remote from the lesion and the integrity of the CST in the subacute-to-chronic period of ICH have been associated with functional motor outcome. ${ }^{19-23}$ An accurate method to individually predict motor outcome within a few hours after ICH would enable realistic goal setting and efficient resource allocation by clinicians, patients, and families, providing them with information that might help choose more efficient rehabilitation programs. Given the lack of studies in the acute phase, we aimed to determine whether combining clinical scores or motor impairment and DTI-derived data of tissue impairment from the first 12 hours after symptom onset allows prediction of motor outcome in patients with ICH.

\section{MATERIALS AND METHODS \\ Patients}

We studied consecutive patients with spontaneous primary $\mathrm{ICH}$ admitted to the Stroke Unit of Dr. Josep Trueta University Hospital from January 2012 through December 2014. Inclusion criteria were the following: 1) patient older than 18 years, 2) first-ever stroke, 3) supratentorial primary intraparenchymal hematoma, 4) presence of motor deficit, 5) MR imaging performed within 12 hours from symptom onset, and 6) clinical follow-up at 90 days. Exclusion criteria were the following: 1) secondary ICH due to vascular malformation, cranial trauma, or tumor; 2) poor premorbid functional status ( $\mathrm{mRS}>2) ; 3$ ) dementia or terminal illness; 4) coma; 5) poor image quality; 6) primary intraventricular hemorrhage; or 7) infratentorial hemorrhage; 8) any contraindications for MR imaging; and 9) surgical treatment. All patients were managed according to recent published guidelines. ${ }^{24}$ Standard rehabilitation programs were initiated once patients were clinically stable. Our institutional ethics committee approved the study, and all patients or their relatives provided written informed consent.

\section{Clinical Examination}

A senior certified staff neurologist used the NIHSS to assess clinical deficits at admission, day 3 , and 3 months. Limb motor performance was evaluated by the mNIHSS subindex (5a, 5b, 6a, 6b).
The scores were summed and defined with paresis grading ranging from zero, no motor weakness, to 8 , hemiplegia in 2 limbs. Motor outcome at 3 months was classified as good ( $\mathrm{mNIHSS} 0-3$ ) or poor (mNIHSS $4-8) .{ }^{20}$ The mRS was used to measure patients' functional disability at 3 months. Poor functional outcome was defined as mRS $>2 .{ }^{25}$ All clinical assessments were blinded to the MR imaging findings.

\section{MR Imaging Protocol}

All scans were performed with a whole-body 1.5T MR imaging system (Gyroscan Intera; Philips Healthcare, Best, the Netherlands) with a sensitivity encoding head coil. The protocol included FLAIR, gradient recalled-echo, TOF angiography, axial trace DWI, and DTI sequences. DTI was performed using a singleshot echo-planar imaging sequence with the sensitivity encoding parallel-imaging scheme (acceleration factor, 2) after contrast agent administration for angiography. A single diffusion-weighted $\mathrm{B}_{0}$ acquisition was obtained, and diffusion-sensitized gradients were applied along 15 noncollinear directions with a b-value of $1000 \mathrm{~s} / \mathrm{mm}^{2}$. Other acquisition parameters were the following: TR/TE, 6795/72 ms; FOV, $230 \times 230 \mathrm{~mm}$; matrix size, $112 \times 112$. DTI voxel size was $2.05 \times 2.0 \times 3 \mathrm{~mm}$. Forty sections covering the brain were obtained parallel to the bicommissural line without intersection gaps. DTI acquisition took 3 minutes 10 seconds. Parameters for FLAIR were the following: TR/TE, 7569/115 ms; flip angle, 90; section thickness, $5 \mathrm{~mm}$; intersection gap, $1 \mathrm{~mm}$; FOV, $230 \times 180$ $\mathrm{mm}$; and brain coverage, $120 \mathrm{~mm}$. Parameters for gradient recalled echo were TR/TE, 1000/30 ms; and the others were the same as for FLAIR.

\section{Diffusion Tensor Tractography Processing and Assessment of CST Involvement by ICH}

Deterministic diffusion tensor tractography was performed using Philips Research Integrated Development Environment (PRIDE; Philips Healthcare) software. Anisotropy maps were obtained using orientation-independent FA, and color FA maps were generated following the standard convention (red, left-right; green, anteroposterior; and blue, superoinferior). Tractography was based on a diffusion tensor deflection algorithm. ${ }^{26}$ The threshold for stopping fiber propagation was FA $<0.2$ and angle $<70^{\circ}$. The seeding method put 1 starting seed randomly inside each voxel with an FA of $>0.4$. To reconstruct the CST, we placed ROIs at the level of the cerebral peduncle and around the corona radiata in the direction-coded color axial sections. Fiber tracts passing through both ROIs were designated as tracts of interest. Exclusion ROIs were drawn around the superior and middle cerebellar peduncles to exclude fibers to the cerebellum, and around a midline sagittal section covering the brain stem and corpus callosum to exclude interhemispheric fibers. ${ }^{15,27}$ The CST depicted was validated using landmarks from neuroanatomy atlases. ${ }^{28}$ To determine which structures had ICH and PHE, we evaluated the centrum semiovale, corona radiata, and PLIC on tractograms superimposed on gradient recalled-echo and FLAIR. The CST was considered affected only when the tractogram passed through the $\mathrm{ICH}$ or/and PHE (Fig 1). In those patients in whom the tractogram was bent over or displaced by the ICH, the CST was considered not affected. These regions were scored on 2 separate occasions 8 weeks 


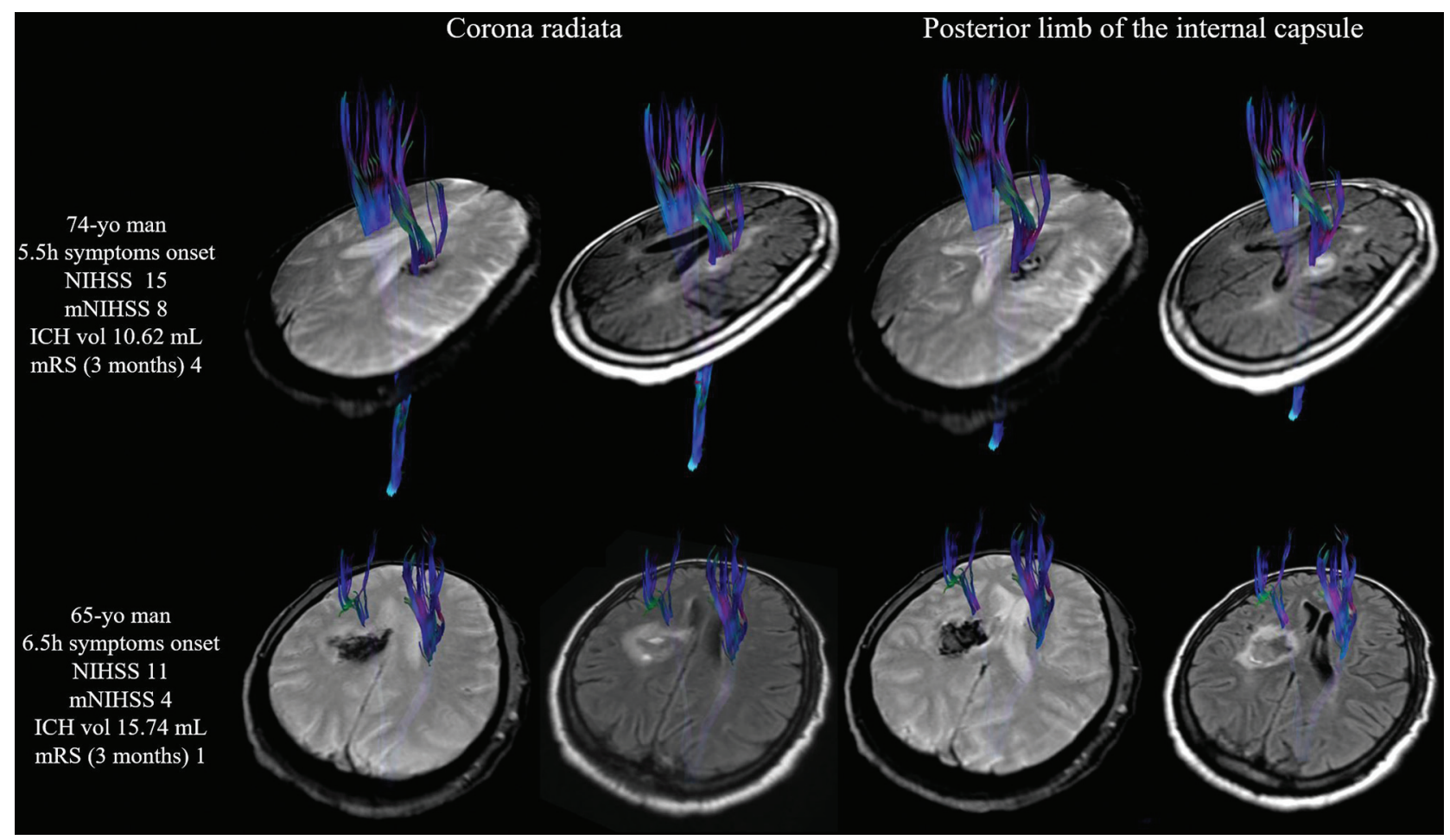

FIG 1. Assessing corticospinal tract involvement with diffusion tensor tractography superimposed on gradient recalled echo and FLAIR images. In the upper row, the corticospinal tract was affected by $\mathrm{ICH}$ (passes through it) at the level of the corona radiata and posterior limb of the internal capsule. Note that in lower row, the corticospinal tract was displaced slightly forward but preserved around the intracerebral hematoma. Vol indicates volume.

apart by 1 rater with 14 years' experience and once by 2 raters ( 14 and 5 years' experience); all raters were blinded to the clinical data. Discordant ratings were resolved by consensus.

\section{Measurement of the CST DTI}

Diffusion-sensitized image sets were analyzed off-line. One reader with 5 years' experience blinded to the clinical scores used Olea Sphere, Version 3.0 software (Olea Medical, La Ciotat, France) to calculate the following DTI measures on 2 separate occasions 4 weeks apart: radial diffusivity, axial diffusivity, mean diffusivity, and FA. The ipsilesional-to-contralesional CST ratios were calculated on axial sections of affected and unaffected CST at the level of the PLIC and at the level of the rostral pons (rDTI-Metric =

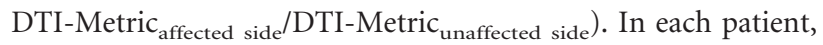
the DTI measures of the CST were derived from the mean value of 3 contiguous sections. The results of the 2 assessments were averaged. Analyzing diffusion tensor tractography took 4 minutes and 30 seconds on average.

\section{Measurement of the ICH and PHE Volumes}

Two independent raters blinded to the clinical data measured ICH and PHE volumes on baseline MR imaging and 72-hour post-ICH CT scans using a semiautomated method (Olea Sphere, Version 3.0). At admission, ICH and PHE volumes were outlined on gradient recalled-echo sequences and FLAIR, respectively. ${ }^{29}$ At 72 hours, PHE was delineated with the additional guideline that it should be more hypodense than the corresponding area in the contralateral hemisphere and most hypodense immediately surrounding the ICH. ${ }^{30}$ Figure 2 de- picts a representative example of a patient's ICH and PHE measurements. The results of the 2 assessments were averaged.

\section{Statistical Analysis}

Descriptive statistics are expressed as medians (interquartile range $[\mathrm{IQR}]$ ) for continuous variables and as frequencies (percentages) for categoric variables. We compared baseline data, clinical variables at admission and at 72 hours, volumes of ICH and PHE, and DTI data between patients with good-versuspoor motor outcome at 3-month follow-up and between patients with $m R S \leq 2$ and $m R S>2$. For univariate comparison, we used $t$ tests for numeric data and the $\chi^{2}$ test for proportions. We used receiver operating characteristic curves to determine cutoffs for variables discriminating motor outcome. Multiple logistic regression was used to define independent predictors of motor outcome (mNIHSS score at 3 months). Several combinations of independent variables were analyzed on the basis of significant univariate $P$ values to ascertain the value of adding CST involvement to the mNIHSS score. We used the Cohen $\kappa$ coefficient to assess intraobserver and interobserver reliability for the assessment of CST involvement by ICH. Intra- and interobserver agreement was classified as slight $(\kappa=0.0-$ $0.20)$, fair $(\kappa=0.21-0.40)$, moderate $(\kappa=0.41-0.60)$, substantial $(\kappa=0.61-0.80)$, or almost perfect $(\kappa=0.81-1.00)$ according to the scale proposed by Landis and Koch. ${ }^{31}$ To compare first and second measurements of DTI measures, we used the intraclass correlation coefficient (ICC). The level of intra- and interobserver consistency was classified as fair 


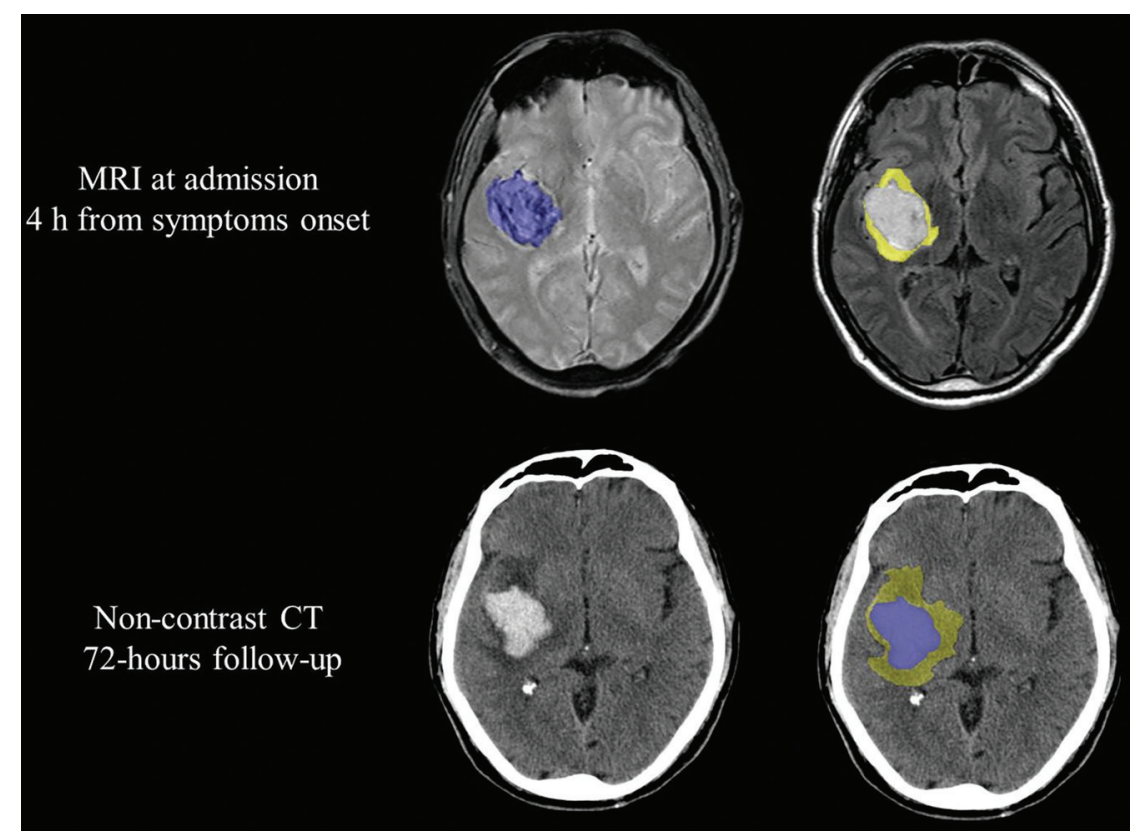

FIG 2. Example of ROI object maps used to measure intracerebral hematoma (blue) and perihematomal edema (yellow) volumes.

$(\mathrm{ICC}=0.5-0.7)$, good $(0.7-0.9)$, or almost perfect $(>0.90)$. All statistical analyses were performed with $\mathrm{R}$, Version 3.0.2 (http://www.r-project.org/).

\section{RESULTS}

\section{Patients}

Among 62 consecutive patients admitted with supratentorial primary ICH conforming to our inclusion criteria, 6 were excluded for not having motor deficits at admission; 6 , for poor image quality due to motion artifacts; and 7 died within 72 hours of symptom onset. Therefore, the study population consisted of 43 patients ( 31 men; mean age 68 years; IQR $=57-76$ years).

\section{Clinical and Neuroimaging Characteristics}

On-line Table 1 summarizes patients' clinical and imaging data according to motor outcomes at 3 months. There were no differences in sex, age, presence of vascular risk factors, and laboratory parameters between 2 groups. At admission, most patients had moderate-to-severe neurologic deficits (NIHSS $=13, \mathrm{IQR}=$ $8-17)$, and $26(60.46 \%)$ of these had moderate-severe motor deficits (mNIHSS $=4-8$ ). At 3 months, 13 (30.23\%) patients had poor motor outcome. Time from ICH onset to MR imaging was 407 minutes ( $\mathrm{IQR}=238-559$ minutes). The most frequent $\mathrm{ICH}$ location was the lenticulostriate territory $(88.1 \%)$. The premorbid mRS was 0 for all patients. CST affected by $\mathrm{ICH}$ was present in 24 (55.8\%) patients; and the PLIC, in 14 (32.5\%) of these patients. All patients with CST affected by ICH had motor deficits at admission. Intrarater and interrater agreement about the CST-involvement region was almost perfect $(\kappa=0.89$ and $\kappa=0.82$, respectively). The intraobserver consistency showed good agreement for CST DTI measures (ICC $=0.81 ; 95 \%$ CI, $0.78-0.86$ ). For ICH and PHE volume assessment, all interrater ICCs were almost perfect at both baseline and 72-hour follow-up
$\left(\mathrm{ICC}_{\mathrm{ICH}-\text { baseline }}=0.96 ; 95 \% \mathrm{CI}, 0.94-\right.$ 1.00 ; ICC $_{\text {PHE-baseline }}=0.95 ; 95 \% \mathrm{CI}$, $0.92-1.00 ; \mathrm{ICC}_{\mathrm{ICH}-72 \text { hours }}=0.98 ; 95 \%$ CI, 0.96-1.00; ICC $_{\text {PHE-72 hours }}=0.98$; 95\% CI, 0.97-1.00).

\section{Analysis of Variables Associated with Clinical Outcome}

In the 13 patients with poor motor outcome at 3 months, NIHSS and mNIHSS scores were higher at admission and at 72 hours than for patients with a good motor outcome (On-line Table 1). Patients with poor motor outcome had higher ICH volume at admission (10.45 $\mathrm{mL} ; \mathrm{IQR}=5.07-15.74 \mathrm{~mL}$ versus 22.74 $\mathrm{mL} ; \mathrm{IQR}=10.3-30 ; P=.034)$ (On-line Table 1). At admission, ICH involved the CST in $11(84.61 \%)$ patients with poor motor outcome and in 13 (43.33\%) patients with good motor outcome $(P=.016)$; ICH involved the PLIC in $9(69.23 \%)$ patients with poor motor outcome $(P=.001)$. Poor motor outcome at 3 months correlated with functional outcome (mRS) at 3 months $(P<.001)$. Patients with poor functional outcome had higher NIHSS and mNIHSS scores at admission and follow-up than patients with good outcome, as well as higher volumes of ICH (On-line Table 2). Poor functional outcome was also associated with CST affected by ICH. CST affected by PHE and quantitative DTI measures did not influence a patient's outcome (Online Tables 1 and 2).

\section{Predictive Models for Functional Motor Outcome}

The best model was obtained by combining the mNIHSS score at 72 hours and PLIC affected by ICH at $<12$ hours (Table). The sensitivity, specificity, and positive and negative predictive values for poor motor outcome at 3 months by combined 72-hour mNIHSS scores of $>3$ and PLIC affected by ICH at $\leq 12$ hours were $92 \%, 86 \%, 75 \%$, and $96 \%$, respectively (area under the curve $=0.94 ; 95 \%$ CI, 0.86-1.00). Additionally, the sensitivity, specificity, and positive and negative predictive values for poor motor outcome at 3 months by combined acute mNIHSS of $>6$ and PLIC involvement of $<12$ hours were $84 \%, 79 \%, 65 \%$, and $92 \%$, respectively (area under the curve $=0.89 ; 95 \%$ CI, $0.78-1$ ).

\section{DISCUSSION}

In this observational study, we analyzed DTI datasets acquired in patients with ICH within 12 hours of symptom onset. We tested whether the combination of clinical scores and DTI-based assessment of CST damage predicts motor function at 3 months in acute ICH. In the first 12 hours of symptom onset, our results suggest that patients with mNIHSS scores of $>6$ and any PLIC affected by $\mathrm{ICH}$ will most probably have poor motor outcome. Kuzu et $\mathrm{al}^{20}$ demonstrated that an mNIHSS score of $\geq 6$ was a strong predictor of motor outcome at 3 months and suggested that patients with an mIHSS score of $\geq 6$ might be considered 
Functional motor outcome prediction: summary of class performance and odds ratios for univariate and multivariate analyses at admission and at $72 \mathrm{hr}$

\begin{tabular}{|c|c|c|c|c|c|c|c|c|}
\hline Variables & Cutoff & $\operatorname{AUC}(95 \% \mathrm{CI})$ & Sensitivity & Specificity & $\begin{array}{l}\text { Positive } \\
\text { Predictive } \\
\text { Value }\end{array}$ & $\begin{array}{l}\text { Negative } \\
\text { Predictive } \\
\text { Value }\end{array}$ & $\begin{array}{c}P \\
\text { Value }\end{array}$ & $\begin{array}{c}\text { Odds } \\
\text { Ratio }(95 \% \mathrm{Cl})\end{array}$ \\
\hline NIHSS score at admission & 15 & $0.77(0.62-0.93)$ & 0.69 & 0.77 & 0.56 & 0.85 & .011 & $1.23(1.05-1.43)$ \\
\hline mNIHSS score at admission & 6 & $0.79(0.64-0.94)$ & 0.77 & 0.77 & 0.59 & 0.88 & .007 & $1.65(1.15-2.36)$ \\
\hline $\mathrm{ICH}$ volume at admission & 17.08 & $0.71(0.54-0.90)$ & 0.38 & 0.86 & 0.50 & 0.80 & .047 & $1.05(1.00-1.10)$ \\
\hline $\begin{array}{l}\text { CST involvement by ICH at } \\
\text { admission }\end{array}$ & Present & $0.70(0.56-0.84)$ & 0.84 & 0.55 & 0.46 & 0.89 & .025 & $6.77(1.27-36.14)$ \\
\hline $\begin{array}{l}\text { PLIC involvement by ICH at } \\
\text { admission }\end{array}$ & Present & $0.76(0.61-0.91)$ & 0.69 & 0.83 & 0.64 & 0.86 & .002 & $10.80(2.36-49.46)$ \\
\hline NIHSS score at $72 \mathrm{hr}$ & 8 & $0.88(0.77-0.99)$ & 0.92 & 0.67 & 0.54 & 0.95 & $<.001$ & $1.31(1.12-1.52)$ \\
\hline $\mathrm{mNIHSS}$ score at $72 \mathrm{hr}$ & 5 & $0.91(0.82-1.00)$ & 0.92 & 0.83 & 0.71 & 0.96 & $<.001$ & $2.10(1.36-3.26)$ \\
\hline $\begin{array}{l}\text { NIHSS score at admission, } \\
\text { PLIC involvement by ICH } \\
\text { at admission }\end{array}$ & $\begin{array}{c}16 \\
\text { Present }\end{array}$ & $0.87(0.75-0.98)$ & 0.85 & 0.86 & 0.73 & 0.93 & $\begin{array}{l}.014 \\
.005\end{array}$ & $\begin{array}{l}1.25(1.05-1.49) \\
14.21(2.23-90.60)\end{array}$ \\
\hline $\begin{array}{l}\text { mNIHSS score at admission, } \\
\text { PLIC involvement by ICH } \\
\text { at admission }\end{array}$ & $\begin{array}{c}6 \\
\text { Present }\end{array}$ & $0.89(0.78-1.00)$ & 0.84 & 0.79 & 0.65 & 0.92 & $\begin{array}{l}.009 \\
.005\end{array}$ & $\begin{array}{c}1.86(1.17-2.94) \\
20.99(2.52-174.80)\end{array}$ \\
\hline $\begin{array}{l}\text { NIHSS score at } 72 \mathrm{hr} \text {, } \\
\text { PLIC involvement by ICH } \\
\text { at admission }\end{array}$ & $\begin{array}{c}14 \\
\text { Present }\end{array}$ & $0.93(0.84-1.00)$ & 0.85 & 0.93 & 0.85 & 0.93 & $\begin{array}{l}.003 \\
.017\end{array}$ & $\begin{array}{c}1.32 \text { (1.10- 1.58), } \\
13.73(1.60-117.65)\end{array}$ \\
\hline $\begin{array}{l}\text { mNIHSS score at } 72 \mathrm{hr} \text {, } \\
\text { PLIC involvement by ICH } \\
\text { at admission }\end{array}$ & $\begin{array}{c}3 \\
\text { Absent }\end{array}$ & $0.94(0.86-1.00)$ & 0.92 & 0.86 & 0.75 & 0.96 & $\begin{array}{l}.005 \\
.020\end{array}$ & $\begin{array}{l}2.08(1.25-3.50) \\
17.04(1.56-186.18)\end{array}$ \\
\hline
\end{tabular}

Note:-AUC indicates area under the curve.

for surgical evacuation of the hematoma. They also reported that absolute FA values of the cerebral peduncle at day 3 were $9 \%$ lower in patients with poor-rather than-good recovery. However, they did not combine the 2 variables to better predict motor outcome. On the other hand, Tao et $\mathrm{al}^{27}$ recently demonstrated that the prognostic value of the ICH score surpassed that of FA values in the CST at the cerebral peduncle within the first 4 days after symptom onset. Combining the FA data with the ICH score did not improve prognostication, probably because 4 days are not enough to detect early Wallerian degeneration in the cerebral peduncle. ${ }^{32}$

We found that ICH volume was a poor predictor of motor outcome at day 90, and motor deficit was present only when critical motor regions were involved, suggesting that large lesions do not necessarily predict poor motor outcome. Thus, growing evidence shows that the preservation and recovery of the CST are crucial for good functional motor outcome. However, we noted that some patients with CST involvement had no motor deficits, presumably due to compensation by alternate motor fibers that contribute to motor control. ${ }^{8}$ In ischemic stroke, functional outcome correlates with the extent of Wallerian degeneration remote from the lesion. In the subacute and the chronic phases of ischemic stroke, FA in the ipsilateral CST decreases progressively in correlation with motor functional outcome. A few studies have demonstrated that reductions in FA values in the acute phase correlate with clinical signs and can predict functional outcome in ICH. ${ }^{19-22}$ Unlike other authors, we found no changes in anisotropy in the cerebral peduncle. Kusano et $\mathrm{al}^{16}$ reported that rFA in the cerebral peduncle correlated negatively with paresis grade and differed significantly at 2 days between patients with good and poor motor outcomes at 28 days. One explanation for these discrepancies is that we examined changes in diffusivity in the first few hours and this time window was too short to detect early signs of Wallerian degeneration. ${ }^{31}$ A recent meta-analysis showed that the studies reported so far on the correlation between FA values and upper extremity motor recovery in patients with $\mathrm{ICH}$ are few with small sample sizes. ${ }^{33}$ This meta-analysis found a strong correlation between FA and upper extremity motor recovery, though the authors concluded that further well-designed prospective studies with larger sample sizes are needed to confirm these findings. ${ }^{33}$

Several limitations warrant comment. This single-center study included too few patients to draw definite conclusions. Future studies with larger samples will enable regression analyses to assess associations in greater detail. We considered clinical follow-up at 3 months because motor recovery seems to occur predominantly in the first few months after stroke; however, some patients with ICH may show further recovery in later phases. ${ }^{2}$ However, an advantage of using a relatively short follow-up is to reduce the possibility of losing patients. The NIHSS is widely used for evaluating patients with acute stroke but might not be good for a fine-grained assessment of motor impairment. The DTI metrics would be difficult to assess, especially when ICH or PHE or both compress the CST, and this may result in variability in location, size, and shape. DTI reflects the averaged water diffusion property within a voxel, which is considered an indirect indicator of the axons; therefore, this model may oversimplify axonal structures. More diffusion gradients would reduce artifacts and increase signal-to-noise ratios. However, increasing the number of directions would have increased the scanning time and decreased the number of patients with a DTI scan without motion artifacts. The diffusion properties of tissues are independent of magnetic field strength. However, the field strength affects the signal-to-noise ratio and artifacts of diffusion-weighted images, which influence the quantitative and spatial accuracy of DTI.

The increased SNR at 3T may be useful for obtaining more accurate diffusion measurements, shortening examination times, 
or improving the spatial resolution. Along this line, DTI studies at 3T using parallel imaging have provided significantly improved DTI measurements relative to studies at $1.5 \mathrm{~T} .{ }^{34}$ Deterministic fiber-tracking methods use a linear propagation approach, proceeding according to the principal eigenvector direction. ${ }^{35}$ This method has poor sensitivity to reconstruct the tracts through regions of crossing fibers. ${ }^{36}$ The presence of the $\mathrm{ICH}$ and/or the PHE could affect the appearance of the CST. By means of probabilistic approaches, the CST would be delineated more extensively. ${ }^{37}$ In fact, the streamline method provides a single estimate of a virtual fiber tract without incorporating the uncertainty introduced by noise, whereas probabilistic approaches attempt to address this limitation by providing a confidence measure. Probabilistic methods provide an arbitrary number of virtual fiber tracts that are reconstructed. ${ }^{38}$ Combining other imaging modalities, such as functional MR imaging or transcranial magnetic stimulation, would increase the accuracy of assessing the neural tracts, therefore, compensating for the limitations of DTI.

We did not assess the impact of the CST distortion of its natural course or whether the additional bending of the CST affected the DTI measures. Secondary lesions due to local intracranial hypertension could be omitted in early DTI scans. Therefore, delineation of the mass effect of PHE and ICH on a later scan performed at around 1 week and used as a covariable could help limit this problem in further studies.

\section{CONCLUSIONS}

Combining mNIHSS and PLIC affected by ICH in the first 12 hours of onset can accurately predict motor outcome. The reliability of DTI in denoting very early damage to the CST could make it a prognostic biomarker useful for determining management strategies to improve outcome in the hyperacute stage. Our approach eliminates the need for advanced postprocessing techniques that are time-consuming and require greater specialization, so it can be applied more widely and benefit more patients. Prospective large-scale studies are warranted to validate these findings and determine whether this information could be used to stratify risk in patients with $\mathrm{ICH}$.

Disclosures: Chase R. Figley—UNRELATED: Employment: University of Manitoba; Grants/Grants Pending: Brain Canada, Health Sciences Centre Foundation, MS Society of Canada, Natural Sciences and Engineering Research Council of Canada Discovery.* Kambiz Nael-UNRELATED: Board Membership: Olea Medical, Comments: Medical Advisory Board. Salvador Pedraza—RELATED: Grant: Fondo de Inversión Sanitaria. Spanish government. ${ }^{*}$ Yolanda Silva-RELATED: Grant: Acadèmia de Ciències Mèdiques de Girona, Comments: I received a grant for $€ 6000$ from the Acadèmia de Ciències Mèdiques de Girona. Josep Puig_RELATED: Grant: Spanish Ministry of Health, Instituto de Investigación Carlos III, Comments: This work was partially supported by a grant from the Spanish Ministry of Health, Instituto de Investigación Carlos III (grant No. 367823-764).* Mikel Terceño-RELATED: Grant: Acadèmia Ciències Mèdiques. * Money paid to the institution.

\section{REFERENCES}

1. Daverat P, Castel JP, Dartigues JF, et al. Death and functional outcome after spontaneous intracerebral hemorrhage: a prospective study of 166 cases using multivariate analysis. Stroke 1991;22:1-6 CrossRef Medline

2. Hendricks HT, van Limbeek J, Geurts AC, et al. Motor recovery after stroke: a systematic review of the literature. Arch Phys Med Rehabil 2002;83:1629-37 CrossRef Medline

3. Feng W, Wang J, Chhatbar PY, et al. Corticospinal tract lesion load: an imaging biomarker for stroke motor outcomes. Ann Neurol 2015;78:860-70 CrossRef Medline

4. Byblow WD, Stinear CM, Barber PA, et al. Proportional recovery after stroke depends on corticomotor integrity. Ann Neurol 2015;78: 848-59 CrossRef Medline

5. Pineiro R, Pendlebury ST, Smith S, et al. Relating MRI changes to motor deficit after ischemic stroke by segmentation of functional motor pathways. Stroke 2000;31:672-79 CrossRef Medline

6. Pendlebury ST, Blamire AM, Lee MA, et al. Axonal injury in the internal capsule correlates with motor impairment after stroke. Stroke 1999;30:956-62 CrossRef Medline

7. Zhu LL, Lindenberg R, Alexander MP, et al. Lesion load of the corticospinal tract predicts motor impairment in chronic stroke. Stroke 2010;41:910-15 CrossRef Medline

8. Lindenberg R, Renga V, Zhu LL, et al. Structural integrity of corticospinal motor fibers predicts motor impairment in chronic stroke. Neurology 2010;74:280-87 CrossRef Medline

9. Zhou Y, Wang Y, Wang J, el al. Inflammation in intracerebral hemorrhage: from mechanisms to clinical translation. Prog Neurobiol 2014;115:25-44 CrossRef Medline

10. Venkatasubramanian C, Kleinman JT, Fischbein NJ, et al. Natural history and prognostic value of corticospinal tract Wallerian degeneration in intracerebral hemorrhage. J Am Heart Assoc 2013;2: e000090 CrossRef Medline

11. Chaudhary N, Pandey AS, Gemmete JJ, et al. Diffusion tensor imaging in hemorrhagic stroke. Exp Neurol 2015;272:88-96 CrossRef Medline

12. Puig J, Pedraza S, Blasco G, et al. Wallerian degeneration in the corticospinal tract evaluated by diffusion tensor imaging correlates with motor deficit 30 days after middle cerebral artery ischemic stroke. AJNR Am J Neuroradiol 2010;31:1324-30 CrossRef Medline

13. Thomalla G, Glauche V, Weiller C, et al. Time course of Wallerian degeneration after ischaemic stroke revealed by diffusion tensor imaging. J Neurol Neurosurg Psychiatry 2005;76:266-68 CrossRef Medline

14. Lindenberg R, Zhu LL, Rüber T, et al. Predicting functional motor potential in chronic stroke patients using diffusion tensor imaging. Hum Brain Mapp 2012;33:1040-51 CrossRef Medline

15. Puig J, Pedraza S, Blasco G, et al. Acute damage to the posterior limb of the internal capsule on diffusion tensor tractography as an early imaging predictor of motor outcome after stroke. AJNR Am J Neuroradiol 2011;32:857-63 CrossRef Medline

16. Kusano Y, Seguchi T, Horiuchi T, et al. Prediction of functional outcome in acute cerebral hemorrhage using diffusion tensor imaging at 3T: a prospective study. AJNR Am J Neuroradiol 2009;30: 1561-65 CrossRef Medline

17. Yoshioka H, Horikoshi T, Aoki S, et al. Diffusion tensor tractography predicts motor functional outcome in patients with spontaneous intracerebral hemorrhage. Neurosurgery 2008;62:97-103 CrossRef Medline

18. Wang DM, Li J, Liu JR, et al. Diffusion tensor imaging predicts long-term motor functional outcome in patients with acute supratentorial intracranial hemorrhage. Cerebrovasc Dis 2012;34:199205 CrossRef Medline

19. Cheng CY, Hsu CY, Huang YC, et al. Motor outcome of deep intracerebral haemorrhage in diffusion tensor imaging: comparison of data from different locations along the corticospinal tract. Neurol Res 2015;37:774-81 CrossRef Medline

20. Kuzu Y, Inoue T, Kanbara Y, et al. Prediction of motor function outcome after intracerebral hemorrhage using fractional anisotropy calculated from diffusion tensor imaging. Cerebrovasc Dis 2012;33:566-73 CrossRef Medline

21. Koyama T, Tsuji M, Miyake H, et al. Motor outcome for patients with acute intracerebral hemorrhage predicted using diffusion tensor imaging: an application of ordinal logistic modeling. J Stroke Cerebrovasc Dis 2012;21:704-11 CrossRef Medline

22. Koyama T, Uchiyama Y, Domen K. Associations of diffusion-tensor fractional anisotropy and FIM outcome assessments after intrace- 
rebral hemorrhage. J Stroke Cerebrovasc Dis. 2018;27:2869-76 CrossRef Medline

23. Koyama $\mathrm{T}$, Tsuji $\mathrm{M}$, Nishimura $\mathrm{H}$, et al. Diffusion tensor imaging for intracerebral hemorrhage outcome prediction: comparison using data from the corona radiata/internal capsule and the cerebral peduncle. J Stroke Cerebrovasc Dis 2013;22:72-79 CrossRef Medline

24. Steiner T, Al-Shahi Salman R, Beer R, et al; European Stroke Organisation. European Stroke Organisation (ESO) guidelines for the management of spontaneous intracerebral hemorrhage. Int J Stroke 2014;9:840-55 CrossRef Medline

25. Sulter G, Steen C, De Keyser J. Use of the Barthel index and modified Rankin scale in acute stroke trials. Stroke 1999;30:1538-41 CrossRef Medline

26. Lazar M, Weinstein DM, Tsuruda JS, et al. White matter tractography using diffusion tensor deflection. Hum Brain Mapp 2003;18: 306-21 CrossRef Medline

27. Tao WD, Wang J, Schlaug G, et al. A comparative study of fractional anisotropy measures and $\mathrm{ICH}$ score in predicting functional outcomes after intracerebral hemorrhage. Neurocrit Care 2014;21: 417-25 CrossRef Medline

28. Wakana S, Jiang H, Nagae-Poetscher LM, et al. Fiber tract-based atlas of human white matter anatomy. Radiology 2004;230:77-87 CrossRef Medline

29. Martin RM, Wright MJ, Lutkenhoff ES, et al. Traumatic hemorrhagic brain injury: impact of location and resorption on cognitive outcome. J Neurosurg 2017;126:796-804 CrossRef Medline
30. Urday S, Beslow LA, Goldstein DW, et al. Measurement of PHE in intracerebral hemorrhage. Stroke 2015;46:1116-19 CrossRef Medline

31. Landis JR, Koch GG. The measurement of observer agreement for categorical data. Biometrics 1977;33:159-74 CrossRef Medline

32. Doughty C, Wang J, Feng W, et al. Detection and predictive value of fractional anisotropy changes of the corticospinal tract in the acute phase of a stroke. Stroke 2016;47:1520-26 CrossRef Medline

33. Kumar P, Yadav AK, Misra S, et al. Prediction of upper extremity motor recovery after subacute intracerebral hemorrhage through diffusion tensor imaging: a systematic review and meta-analysis. Neuroradiology 2016;58:1043-50 CrossRef Medline

34. Alexander AL, Lee JE, Wu YC, et al. Comparison of diffusion tensor imaging measurements at $3.0 \mathrm{~T}$ versus $1.5 \mathrm{~T}$ with and without parallel imaging. Neuroimaging Clin N Am 2006;16:299-309, xi CrossRef Medline

35. Mori S. Fiber tracking: principles and strategies-a technical review. NMR Biomed 2002;15:468-80 CrossRef Medline

36. Mandelli ML, Berger MS, Bucci M, et al. Quantifying accuracy and precision of diffusion MR tractography of the corticospinal tract in brain tumors. J Neurosurg 2014;121:349-58 CrossRef Medline

37. Chung S, Lu Y, Henry RG. Comparison of bootstrap approaches for estimation of uncertainties of DTI parameters. Neuroimage 2006; 33:531-41 CrossRef Medline

38. Alexander AL, Lee JE, Lazar M, et al. Diffusion tensor imaging of the brain. Neurotherapeutics 2007;4:316-29 CrossRef Medline 